\title{
Abacavir versus Zidovudine-based regimens for treatment of HIV-infected children in resource limited settings: a retrospective cohort study
}

Teshale Ayele Mega', Firehiwot Belayneh Usamo ${ }^{1,2}$ and Getandale Zeleke Negera ${ }^{1 *}$ (1)

\begin{abstract}
Background: Abacavir (ABC) and Zidovudine (AZT) based regimens are the preferred first line nucleoside reverse transcriptase (NRTIs) backbones being widely utilized for managing HIV infection in children. However, there is a dearth of data regarding the clinical outcomes and associated risk factors in Ethiopia. We compared the proportion of mortality and the rate of occurrence of Opportunistic Infections (OIs) with ABC versus AZT -based regimens in a cohort of HIV-infected children.
\end{abstract}

Methods: A 42 months retrospective cohort study was conducted. A total of 179 records were reviewed by including data from October 2014 to April 2017. Data were collected on socio-demographic, clinical characteristics of patients and drug related variables. Data were analyzed using STATA13.1. Kaplan-Meier and Cox regression were used to compare survival experience and identify independent predictors. Propensity score matching analysis was conducted to elucidate the average treatment effects of each regimen over Ols.

Result: Of 179 patients, 98 (54.7\%) were females. The mean ( $(+\mathrm{SD})$ age of the study subjects was $6.53 \pm 2.83$ years. Through 42 months analysis, a total of 4 patients (1 (1.14\%) from ABC group and $3(3.3 \%)$ from AZT group $(p=0.339)$ ) were died. The incidence of opportunistic infections attributed to ABC group was 8.77/100,000 person years (py) and that of AZT was 6.9/100,000py. The incidence rate ratio (IRR) for Ols was (IRR $=0.87,95 \% \mathrm{Cl}[0.49-1.53](p=0.304)$. Baseline CD4 count (AHR =0.99, 95\% Cl [0.98-0.99]), Severe acute malnutrition (AHR =15.92, 95\% Cl [5.34-47.50]), and exposure to tuberculosis treatment $(\mathrm{AHR}=2.93,95 \% \mathrm{Cl}[1.39-6.17])$ were the independent predictors for the development of Ols.

Conclusion: $A B C$ and AZT based ART regimens seem to have comparable survival benefit among HIV-infected children in Ethiopia. Therefore, both regimens might be used as an alternative in resource limited settings.

Keywords: HIV, Abacavir, Zidovudine, Clinical outcome, Jimma medical Centre, Ethiopia

\footnotetext{
* Correspondence: getandale@gmail.com

'Department of clinical pharmacy, School of Pharmacy, Institute of Health Sciences, Jimma University, Jimma, Ethiopia

Full list of author information is available at the end of the article
}

(c) The Author(s). 2020 Open Access This article is licensed under a Creative Commons Attribution 4.0 International License, which permits use, sharing, adaptation, distribution and reproduction in any medium or format, as long as you give appropriate credit to the original author(s) and the source, provide a link to the Creative Commons licence, and indicate if changes were made. The images or other third party material in this article are included in the article's Creative Commons licence, unless indicated otherwise in a credit line to the material. If material is not included in the article's Creative Commons licence and your intended use is not permitted by statutory regulation or exceeds the permitted use, you will need to obtain permission directly from the copyright holder. To view a copy of this licence, visit http://creativecommons.org/licenses/by/4.0/ The Creative Commons Public Domain Dedication waiver (http://creativecommons.org/publicdomain/zero/1.0/) applies to the data made available in this article, unless otherwise stated in a credit line to the data. 


\section{Background}

Globally, an estimated 2.4 million children are living with Human Immune Virus (HIV) and 91\% of them are lived in Sub-Saharan Africa [1, 2]. Ethiopia has the largest populations of HIV-infected children in the region. According to an estimate by the Federal HIV/AIDS Prevention and Control Office (FHAPCO), there are over 738,976 people living with HIV/AIDS in Ethiopia [3]. Of these, 178,500 are children younger than 15 years of age [4].

The introduction of Antiretroviral Therapy (ART) had resulted in dramatical reduction of HIV associated morbidity and mortality in children $[5,6]$. However, less than $25 \%$ of those needing ART were receiving it in Ethiopia [4].

Initially, a fixed-dose combination (FDC) of Stavudine (d4T), Lamivudine (3TC) and Nevirapine (NVP) was used for the treatment of children [7]. But in 2010, the World Health Organization (WHO) guideline replaced $\mathrm{d} 4 \mathrm{~T}$ with $\mathrm{ABC}$ due to toxicity concerns [8]. The current ART guidelines recommends 3TC with either ABC or AZT as the preferred nucleoside reverse-transcriptase inhibitors (NRTIs) backbone for children [9]. Tenofovir (TDF) is not recommended by WHO in those younger than 10 years, because of its long-term effects on bone metabolism and renal function [10]. Zidovudine is associated with bone marrow suppression, particular in malnourished children [11]. Whereas ABC is linked with hypersensitivity reactions, especially in patients who are positive for the $H L A-B * 5701$ allele, although these are rare in Africa because of a lower risk-allele prevalence $[12,13]$.

A wide range of randomized clinical trials (RCTs) are conducted to provide a robust evidence base for the treatment of adults with combination of ART [14-17]. In contrast, studies comparing different ART combinations are few in children. Although, the available studies demonstrated comparable or greater efficacy and safety of ABC compared with AZT in combination therapy regarding virological response and adverse effect $[11,18,19]$, the effect of $\mathrm{ABC}$ on survival and factors influencing the occurrence of OIs and mortality in low income nations are rarely evaluated.

After 2 years of 2010 WHO guideline recommendation, Ethiopia implemented the $\mathrm{d} 4 \mathrm{~T}$ phase-out program and $\mathrm{ABC}$ becomes routinely utilized in the current practice setup since 2012 [20]. However, there is no study comparing the relative efficacy of $\mathrm{ABC}$ and $\mathrm{AZT}$ in HIV-infected children in Ethiopia. A recent study conducted in South Africa reported that children who were on $\mathrm{ABC}$ based regimen had lower proportion of death compared with those on d4T, even though it's not statistically significant [21]. In this study, we compared the clinical outcomes of $\mathrm{ABC}$ versus $\mathrm{AZT}$ in combination with $3 \mathrm{TC}$ in terms of their clinical effects and associated risk factors in a cohort of HIV-infected Ethiopian children.

\section{Methods \\ Study design and setting}

A retrospective cohort study was conducted among 179 HIV-infected children in Jimma Medical Center (JMC). The study was conducted from April 10 to May 10, 2017 by including data from October 2014 to April 2017. JMC is located in Jimma town, $355 \mathrm{~km}$ from Addis Ababa. It is currently the only teaching and specialized hospital in the southwest region of Ethiopia. The hospital serves as a referral site and provides specialized care for Southwest Ethiopia with a catchment population of about 15 million.

\section{Study population and variables}

We included HIV-infected children ( $<15$ years) who were on $\mathrm{ABC}$ and AZT based regimens between October 2014 and April 2017 that fulfill the eligibility criteria. Patients on ABC and AZT based first line regimens, having at least 6 months of follow-up with good adherence, whose records were legible and complete, who have CD4 count at least at base line and 6 months and younger than 15 years, included in the study. Those transferred out within $<6$ months of follow up, and patients with incomplete records were excluded. The study was conducted by dividing the total sample in two major classes as ABC group and AZT group.

Data were collected on socio-demographic characteristics (age, sex, area of residence, weight $(\mathrm{kg})$, height $(\mathrm{cm})$, body mass index (BMI)), Diseases Related Factors (CD4 count, WHO clinical stage), Treatment Related Factors (types of ART regimen, Opportunistic Infection (OI) prophylaxis (Cotrimoxazole Prevention Therapy (CPT), Isoniazid Preventive Therapy (IPT), anti-tubercular drug treatment) and clinical outcomes (mortality, occurrence of OIs).

\section{Patient enrolment}

The number of patient charts who fulfilled the eligibility criteria from $\mathrm{ABC}$ group was very limited. i.e. 87 patient charts only. Hence, we included all of them. On the other hand, there were about 203 eligible patient charts from AZT group. Hence, a simple random sampling technique was used to select 92 patient charts from AZT group, making the ABC to AZT group ratio of 1:1.05. Therefore, a total of 179 patient charts, 87 charts from $\mathrm{ABC}$ and 92 charts from AZT group were included in the final analysis (Fig. 1).

\section{Data collection procedure and quality assurance}

Data on demographic, clinical, laboratory, and drug administered, were collected by record review using English version checklist. The data collection tool was carefully prepared after reviewing relevant literatures to 


\section{Results}

\section{Overview of the study participants}

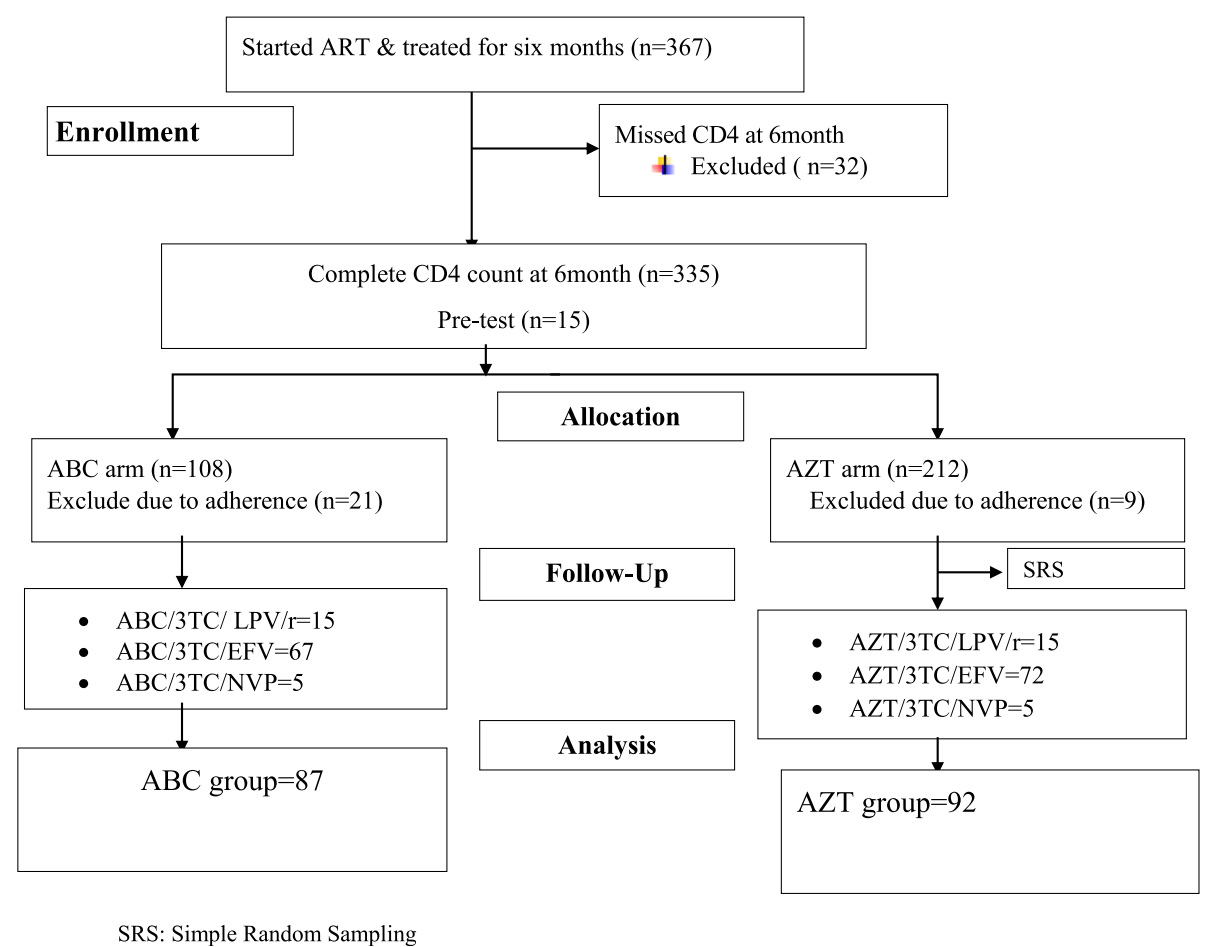

Fig. 1 Sample recruitment chart at JMC; of patients attending ART clinic, April 10-May 10, 2017

enable the data collectors to gather all the information required to address the study objectives. A 2-day training was provided on the data collection tool and the general procedures for data collectors i.e. 2 pharmacists (B.Pharm) and 2 nurses, and one medical interns who were acting as supervisor. Pharmacists collected data regarding antiretroviral drugs, and nurses collected patient information from patient chart, ART clinic intake form, and HIV care/ART follow up. Baseline body mass index of the subjects was later calculated after collection of baseline height and weight of the patient from patients chart. Pre-test was conducted on $5 \%$ of the eligible records.

\section{Ethical consideration}

The study was approved by Institutional Review Board (IRB) of Jimma University. It has designated with an IRB number of IHRPGB/112/2017. The need for informed consent was waived because of the retrospective, anonymous nature of the study. During data collection, confidentiality was ensured and for this reason, name and address of the patient was not recorded in the data collection check list.

\section{Statistical analysis}

Data were entered into Epi-Data and exported to STATA 13.1 for cleaning and analysis. Descriptive analysis was performed and results were presented by text, tables and charts. Kaplan-Meier (log rank test) was used to compare baseline survival characteristics of the patients for opportunistic infections. Chi-square test was performed to check adequacy of cells before performing Cox regression. Cox regression model assumption of proportional hazards was checked by testing an interaction of covariates with time. Bivariate Cox regression was performed to identify candidate variables for multivariable Cox regressions. Variables with $p$-value $\leq 0.25$ in bivariate regression were considered as candidates for multivariable regression. Multivariable Cox regression was performed to identify independent predictors of opportunistic infections. Hazard ratio with $95 \%$ confidence intervals was used as a measure of strength of association and p-value $<0.05$ was considered to declare a statistical significance. Finally, a matching estimator, propensity score matching was conducted to estimate the average treatment effect of $\mathrm{ABC}$ based regimen on the opportunistic infection considering AZT based regimen as a reference regimen. This is a robust analytical method which uses the idea of randomized clinical trials with an assumption of unconfoundedness. So, it is a better analysis method to show the true result of an intervention in observational studies. It is a matching technique (estimator) that uses the idea of randomized 
controlled studies in which the impact of confounding variables is minimized.

\section{Operational definition of terms}

Good adherence: estimated adherence level of $>95 \%$ [22] as recorded by ARTphysicians/Nurses.

Child: Age $<15$ years [4].

Incident OIs: The onset of new infection after 3 months of ART initiation in a patient initially free of any clinically evident infection [23].

Lost to follow-up: Refers to a patient who has missed clinical or drug pick-up appointment permanently [24].

\section{Results}

\section{Overview of the study participants}

A total of 367 patients started antiretroviral therapy (ART) and treated for at least 6 months. Of these, 108 from $\mathrm{ABC}$ group, and 212 from AZT group have complete
CD4+ count at the 6th month of treatment. Thirty two patients were excluded initially from either regimens due to missed CD4+ count at 6 month, 30 (21 and 9 from $\mathrm{ABC}$ and AZT respectively) because of adherence problems, and 179 patients were included in the analysis (Fig. 1).

The overall analysis time at risk was 48,330 days. The mean \pm standard deviation (SD) duration of follow up was $939.8+478.3$ and $984.92+453.1$ days for $A B C$ and AZT groups respectively.

\section{Descriptive analysis of baseline characteristics}

Of 179 patients, 98 (54.7\%) were females. The mean \pm SD age of the study participants was $6.6+2.8$ and $6.5+2.9$ years for ABC and AZT groups respectively $(p=0.25)$.

At baseline, the mean \pm SD CD4 T Lymphocyte count was $166.3+76.22$ and $178.8+71.12$ cells $/ \mathrm{mm}^{3}$ for $\mathrm{ABC}$ and AZT groups, respectively $(p=0.26)$. The comparative

Table 1 Comparative baseline characteristics of the cohort at JMC, April 10-May 10, 2017

\begin{tabular}{|c|c|c|c|c|}
\hline \multicolumn{2}{|l|}{ All $n=179$} & \multirow{2}{*}{$\begin{array}{l}\text { ABC group } \\
(n=87)\end{array}$} & \multirow{2}{*}{$\begin{array}{l}\text { AZT group } \\
(n=92)\end{array}$} & \multirow[t]{2}{*}{$P$-value } \\
\hline Variables & & & & \\
\hline \multirow[t]{2}{*}{ Sex } & Male & $42(48.3 \%)$ & $39(42.4 \%)$ & 0.42 \\
\hline & Female & $45(51.7 \%)$ & $53(57.6 \%)$ & \\
\hline \multirow[t]{3}{*}{ Age (years) } & $<3$ years & $11(12.6 \%)$ & $12(13.0 \%)$ & 0.97 \\
\hline & $3-5$ years & $18(20.7 \%)$ & $20(21.7 \%)$ & \\
\hline & $>5$ years & $58(66.7 \%)$ & $60(65.2 \%)$ & \\
\hline \multirow[t]{2}{*}{ BMI (baseline) } & $<5$ th centile & $74(85.0 \%)$ & $66(71.7 \%)$ & 0.03 \\
\hline & $>5$ th centile & $13(14.9 \%)$ & $26(28.3 \%)$ & \\
\hline \multirow[t]{2}{*}{ Maternal HIV status } & Positive & 78 (89.7\%) & $83(90.2 \%)$ & 0.91 \\
\hline & Unknown & $9(10.3 \%)$ & $9(9.8 \%)$ & \\
\hline \multirow[t]{2}{*}{ Area of residence } & Urban & 66 (75.9\%) & $68(73.9 \%)$ & 0.76 \\
\hline & Rural & $21(24.1 \%)$ & $24(26.1 \%)$ & \\
\hline Baseline CD4+ (Mean \pm SD) & & $166.31 \pm 76.22$ & $178.78+71.12$ & 0.26 \\
\hline \multirow[t]{4}{*}{ WHO stage } & । & $8(9.2 \%)$ & $3(3.3 \%)$ & 0.08 \\
\hline & $\|$ & $24(27.6 \%)$ & $40(43.5 \%)$ & \\
\hline & III & $45(51.7 \%)$ & $42(45.7 \%)$ & \\
\hline & IV & $10(11.5 \%)$ & $7(7.6 \%)$ & \\
\hline \multirow[t]{3}{*}{ Functional status } & W/A & $72(82.8 \%)$ & $88(95.7 \%)$ & 0.001 \\
\hline & $A / D$ & $12(13.8 \%)$ & $0(0.0 \%)$ & \\
\hline & $B / R$ & $3(3.4 \%)$ & $4(4.3 \%)$ & \\
\hline \multirow[t]{2}{*}{ TB (treatment) } & Yes & $3(3.4 \%)$ & $9(9.8 \%)$ & 0.06 \\
\hline & No & 84 (96.6\%) & $83(90.2 \%)$ & \\
\hline \multirow[t]{3}{*}{ Ol Prophylaxis } & Both CPT and INH & 85 (97.7\%) & 89 (96.7\%) & 0.69 \\
\hline & CPT only & $1(1.1 \%)$ & $1(1.1 \%)$ & \\
\hline & Neither & $1(1.1 \%)$ & $2(2.2 \%)$ & \\
\hline \multirow[t]{2}{*}{ Nutritional status } & Normal & $45(51.7 \%)$ & 57 (62.0\%) & 0.17 \\
\hline & SAM & $42(48.3 \%)$ & 35 (38.0\%) & \\
\hline
\end{tabular}


baseline characteristics of the study subjects are depicted in Table 1.

\section{Clinical outcomes}

Mortality During the study period, a total of 4 patients (1(1.14\%) patient from $\mathrm{ABC}$ group and 3 (3.3\%) from AZT group; $p=0.339$ ) died.

Opportunistic infections A total of 58 patients with opportunistic infections were identified, making the overall incidence of opportunistic infection among the cohort 3.9/100,000 person years (py). Most of the OIs were reported from AZT +3TC + EFV (24/71) and ABC $+3 \mathrm{TC}+\mathrm{EFV}(23 / 68)$. Other regimens contributed as follows: $\mathrm{ABC}+3 \mathrm{TC}+\mathrm{Lop} / \mathrm{r}(5 / 15), \mathrm{AZT}+3 \mathrm{TC}+\mathrm{Lop} / \mathrm{r}$ (5/ 15) and $A B C+3 T C+N V P(1 / 5)$. There is no report of OI from AZT + 3TC + NVP regimen. Bacterial pneumonia was reported to be the leading OI (Table 2).

There were 16/87 from $A B C$ group and 15/92 from AZT cases of pneumonia. The incidence of opportunistic infection attributed to $\mathrm{ABC}$ group was $8.77 / 100$, 000py] and that of AZT was 6.9/100,000py. The incidence rate ratio (IRR) was found to be $0.87,95 \%$ CI [0.49-1.53], implying that the difference is statistically insignificant $(p=0.304)$. Similarly, the overall median survival time for the cohort was 275 (107-526) days. The median survival time belongs to AZT group was 366 (86-676) days and that of ABC group was 273 (123-569) days ( $\log$ rank $p=0.38)$. See Fig. 2 below.

\section{Results of treatment effect analysis}

We carried out a robust analysis to estimate the unconfounded effect of $\mathrm{ABC}$ based regimen on the occurrence of opportunistic infections both at the population level and among those who received the actual treatment. Because adherence is critical variable, we only included patients with good adherence.

Table 2 Opportunistic infections diagnosed in the cohort at JMC, April 10-May 10, 2017

\begin{tabular}{ll}
\hline Type of opportunistic infections & Frequency (\%) \\
\hline Bacterial Pneumonia & $42(53.8)$ \\
Diarrhea & $9(11.5)$ \\
Candidiasis & $9(11.5)$ \\
Pneumonia + Pulmonary TB & $9(11.5)$ \\
Pneumocystis pneumonia (PCP) & $6(7.7)$ \\
Herpes zoster + Candidiasis & $6(7.7)$ \\
Pneumonia + Disseminated TB & $6(7.7)$ \\
Herpes zoster & $6(7.7)$ \\
Pulmonary TB & $3(3.8)$ \\
\hline
\end{tabular}

TB Tuberculosis; PCP Pneumocystis jiroveci Pneumonia
In the analysis, the occurrence of opportunistic infections was considered as an outcome dependent variable and treatment group was considered as treatment dependent variable. After adjusting for sex, age, base line body mass index, weight for height, in care of the child, maternal status, paternal status, residence, baseline CD4 count, viral load, WHO Stage, nutritional status, and exposure to anti-tubercular drugs, the propensity score matching analysis failed to show the superiority of $A B C$ based regimen in suppressing $\mathrm{OI}$ at both population level $(\beta=0.0112, p=0.844)$ and among those who received the actual treatment $(\beta=0.0217, p=0.772)$ (Table 3). Although it seems there was 22 excess opportunistic infections in $\mathrm{ABC}$ group among 1000 patients who received the actual therapy, the finding is statistically insignificant $(\mathrm{p}=0.772)$ (Table 3). This section of analysis was also in line with the Kaplan-Mayer survival analysis output shown in Fig. 2 above.

$A T E$ Estimated average treatment effect in the population, ATET Estimated average treatment among treated, $C I$ Confidence interval, $A I$ Abadie-imbens

\section{Predictors of opportunistic infections}

After checking for model fitness and considering all the assumptions, a Cox-proportional hazard regression was conducted to identify predictors for the development of OIs. On bivariate Cox-regression, baseline body mass index, baseline weight for height (WFH), area of residence, baseline CD4 count, baseline viral load, WHO clinical stages, nutritional status and exposure to antitubercular drugs were associated with the development of OIs. After adjusting all the confounders with Coxproportional hazard model, baseline CD4 count, exposure to anti-tubercular drugs and nutritional status remained independent predictors of OIs. Accordingly, there was a $1 \%$ reduction in the hazard of OIs development as median baseline CD4 count increased by a unit (AHR $=0.99,95 \%$ CI [0.98-0.99]. However, hazard of OIs in paediatric patients with malnutrition is extremely high (AHR = 15.92 [5.34-47.50]). Moreover, exposure to tuberculosis treatment had also carried significant risk of OIs, $($ AHR $=2.93$ [1.39-6.17]) (Table 4). Functional status and OIs prophylaxis were removed from the analysis, as they did not pass the cell adequacy test.

\section{Discussion}

This is the first study to compare the clinical outcomes of ABC and AZT based regimens among HIV-infected children in Ethiopia. Our analysis showed that overall there was no difference in mortality and occurrence of OIs between children receiving ABC or AZT based ART in JMC, Ethiopia (Fig. 2, Tables 3 and 4). 


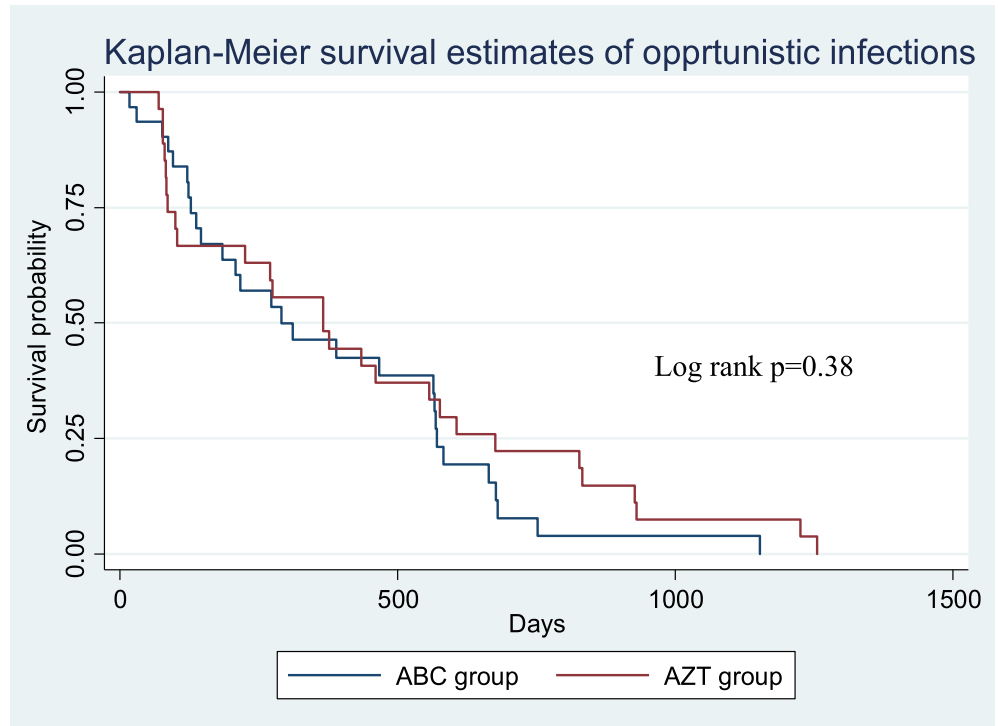

Fig. 2 The cumulative survival probability for the occurrence of opportunistic infections among paediatrics exposed to ABC versus AZT in Jimma medical centre, from April 10-May 10, 2017

Baseline CD4 count, nutritional status, and exposure to tuberculosis treatment were the independent predictors for the development of OIs.

The reported mortality between the ABC and AZT groups was statistically insignificant. There was only 1 (1.14\%) death from $\mathrm{ABC}$ group and 3 (3.3\%) deaths from AZT group $(p=0.339)$. Similarly, there was no difference in the incidence of opportunistic infection $(\mathrm{IRR}=0.87,95 \%$ CI $[0.49-1.53, p=0.304)$. Moreover, the finding from propensity score matching showed statistically insignificant difference of $A B C$ based regimen's effect on opportunistic infections $(\beta=0.0217$, $p=0.772$ ). A similar finding was obtained in the CHAPAS-3 study. This RCT compared the NRTIs $\mathrm{ABC}, \mathrm{AZT}$ and $\mathrm{d} 4 \mathrm{~T}$ in HIV-infected African children, and found that all three NRTIs had similar outcomes in terms of clinical, immunological and virological responses [11]. A finding by Adetokunboh et al. also concluded that $A B C$ based regimen in children had similar efficacy and safety profile with AZT based regimens [25]. In contrary, the PENTA-5 trial demonstrated greater efficacy of $\mathrm{ABC}$ based regimen over AZT [18]. This difference could be attributed to study design, sample size (179 vs.128 subjects), inclusion of patients only with good adherence, and exclusion of patients with follow-up less than 6 months.

This study showed that baseline CD4 count was strongly associated with the development of OIs. Accordingly, there was a $1 \%$ reduction in the hazard of OIs development as median baseline CD4 count increased by a unit $(\mathrm{AHR}=0.99,95 \%$ CI $[0.98-0.99]$ ) . Similar findings were found from Ethiopia [26] and Nigeria [27].

However, paediatric patients with malnutrition had extremely high risk of having opportunistic infections $(\mathrm{AHR}=15.92,95 \%$ CI [5.34-47.50]), similar to studies in Ethiopia [28], Nigeria [27] and Cambodia [29]. Malnutrition aggravates the underlying immunosuppression enhancing their susceptibility to various opportunistic infections and HIV disease progression $[30,31]$.

Moreover, exposure to tuberculosis treatment had also carried significant risk of OIs. Accordingly, patients with anti-tubercular drug treatment were three times at higher risk of having opportunistic infections $(\mathrm{AHR}=$ 2.93, 95\% CI [1.39-6.17]). This might be related to the

Table 3 The estimated average treatment effect of $A B C$ based regimen on opportunistic infections at JMC

\begin{tabular}{|c|c|c|c|c|c|}
\hline \multicolumn{2}{|c|}{ Treatment group } & \multirow{2}{*}{$\frac{\text { Coefficient }(\beta)}{\text { Base Regimen }}$} & \multirow[t]{2}{*}{ Al Robust Standard Errors } & \multirow[t]{2}{*}{$p$} & \multirow[t]{2}{*}{$95 \% \mathrm{Cl}$} \\
\hline$\overline{\mathrm{AZT}}$ & & & & & \\
\hline \multirow[t]{2}{*}{$A B C$} & ATE & 0.0112 & 0.0566 & 0.844 & $-0.0998,0.1221$ \\
\hline & ATET & 0.0217 & 0.0750 & 0.772 & $-0.1253,0.1688$ \\
\hline
\end{tabular}


Table 4 Crude and adjusted Cox-proportional hazard regression output for the predictors of opportunistic infections among HIV -infected paediatrics at JMC, April 10-May 10, 2017

\begin{tabular}{|c|c|c|c|c|c|c|c|}
\hline \multirow[t]{2}{*}{ Variables } & & \multicolumn{2}{|l|}{ Ols } & \multirow[t]{2}{*}{ CHR $[95 \% \mathrm{Cl}]$} & \multirow[t]{2}{*}{$p$-value } & \multirow[t]{2}{*}{ AHR[95\%Cl] } & \multirow[t]{2}{*}{$p$-value } \\
\hline & & Yes & No & & & & \\
\hline \multirow[t]{2}{*}{ Sex } & Male & $30(30.6$ & $68(69.4)$ & 1 & & & \\
\hline & Female & $28(34.6)$ & $53(65.4)$ & $0.94[0.55-1.59]$ & 0.810 & & \\
\hline Age: Median IQR & $7(4-9)$ & $58(32.4)$ & $121(67.6)$ & $1.00[0.91-1.09]$ & 0.995 & & \\
\hline \multirow[t]{2}{*}{ Base-line body mass index } & Below 5th centile & $53(37.9)$ & $87(62.1)$ & $3.63[1.45-9.10]$ & 0.006 & & \\
\hline & Above $5^{\text {th }}$ centile & $5(12.8)$ & $34(87.2)$ & 1 & & & \\
\hline \multirow[t]{3}{*}{ Weight for height } & $\leq 70 \%$ & $15(41.7)$ & $21(58.3)$ & $1.34[0.74-2.44]$ & 0.332 & & \\
\hline & $70-85 \%$ & $2(14.3)$ & $12(85.7)$ & $0.42[0.10-1.73]$ & 0.229 & & \\
\hline & $\geq 85 \%$ & $41(31.8)$ & $88(68.2)$ & 1 & & & \\
\hline \multirow[t]{2}{*}{ In care of the child } & Mother & $7(29.2)$ & $17(70.8)$ & 1 & & & \\
\hline & Other & $51(32.9)$ & $104(67.1)$ & $0.66[0.28-1.54]$ & 0.332 & & \\
\hline \multirow[t]{2}{*}{ Maternal status } & Live & $47(32.2)$ & $99(67.8)$ & 1 & & & \\
\hline & Dead & $11(33.3)$ & $22(66.7)$ & $1.17[0.59-2.32]$ & 0.654 & & \\
\hline \multirow[t]{2}{*}{ Maternal sero-status } & Unknown & $6(33.3)$ & $12(66.7)$ & $0.71[0.28-1.81]$ & 0.476 & & \\
\hline & Negative & $52(32.3)$ & $109(67.7)$ & 1 & & & \\
\hline \multirow[t]{2}{*}{ Paternal status } & Live & $43(32.6)$ & $89(67.4)$ & 1 & & & \\
\hline & Dead & $15(31.9)$ & $32(68.1)$ & $0.88[0.48-1.62]$ & 0.694 & & \\
\hline \multirow[t]{2}{*}{ Residence } & Urban & 49 (36.6) & $85(63.4)$ & 1 & & & \\
\hline & Rural & $9(20)$ & $36(80)$ & $1.81[0.885-3.69]$ & 0.104 & & \\
\hline \multirow[t]{2}{*}{ ART group } & $A B C$ & $27(31)$ & $60(69)$ & $1.05[0.62-1.76]$ & 0.885 & & \\
\hline & AZT & $29(31.5)$ & $63(68.5)$ & 1 & & & \\
\hline CD4 count $^{a}$ & $162(117-221)$ & $58(32.4)$ & $121(67.6)$ & $0.98[0.97-0.98]$ & $\leq 0.001$ & $0.99[0.98-0.99]$ & $\leq 0.001$ \\
\hline \multirow[t]{2}{*}{ Baseline Viral load } & $\leq 1000 \mathrm{copes} / \mathrm{ml}$ & $36(24.7)$ & $110(75.3)$ & 1 & & 1 & \\
\hline & $>1000$ copes $/ \mathrm{ml}$ & $19(65.5)$ & $10(34.5)$ & $2.87[1.62-5.10]$ & $\leq 0.001$ & $1.72[0.91-3.24]$ & 0.094 \\
\hline \multirow[t]{4}{*}{ WHO Stage } & Stage I & $5(45.5)$ & $6(54.5)$ & 1 & & & \\
\hline & Stage ॥ & $15(23.4)$ & $49(76.6)$ & $0.39[0.14-1.06]$ & 0.066 & & \\
\hline & Stage III & 31 (35.6) & $56(64.4)$ & $0.59[0.23-1.52]$ & 0.276 & & \\
\hline & Stage IV & $7(41.2)$ & $10(58.8)$ & $0.80[0.25-2.53]$ & 0.707 & & \\
\hline \multirow[t]{2}{*}{ Baseline nutritional status } & Normal & $4(3.9)$ & $98(96.1)$ & 1 & & 1 & \\
\hline & SAM & $54(70.1)$ & $23(29.9)$ & 28.37 [10.23-78.73] & $\leq 0.001$ & $15.92[5.34-47.50]$ & $\leq 0.001$ \\
\hline \multirow[t]{2}{*}{ TB treatment } & No & $46(27.7)$ & $120(72.3)$ & 1 & & 1 & \\
\hline & Yes & $12(92.3)$ & $1(7.7)$ & 8.58 [4.33-17.01] & $\leq 0.001$ & $2.93[1.39-6.17]$ & 0.005 \\
\hline
\end{tabular}

CHR Crude hazard ratio, AHR Adjusted hazard ratio, ABC Abacavir, ART antiretroviral therapy, AZT Azidothymidine, WHO world health organization, TB Tuberculosis ${ }^{a}$ Baseline CD4 count expressed in median and interquartile range (IQR)

killing of mycobacteria by anti-tubercular drugs releasing large amounts of mycobacterial antigens, which can stimulate an exuberant inflammatory response. The resulting excessive inflammatory response leads to unmasking of an underlying occult opportunistic infections [32].

The results of our study should be interpreted in the context of several possible limitations. Firstly, as the sample size was relatively small the power to detect definitive differences may have been limited. Measure of adherence by health professionals that may not fit to the reality, and inability to assess the occurrence of specific OIs are some of the limitations.

\section{Conclusion}

In present study, there was no statistically significant difference in mortality and occurrence of opportunistic infections between those exposed to $\mathrm{ABC}$ versus AZT based regimens. Baseline CD4 count, nutritional status, and exposure to tuberculosis treatment were 
the independent predictors for the development of OIs. The study highlighted the need for special attention for these patients groups over the course of treatment provision.

\section{Abbreviations}

AHR: Adjusted Hazard Ratio; ART: Antiretroviral Therapy; CHR: Crude Hazard Ratio; Cl: Confidence interval; HIV: Human Immune Virus; JMC: Jimma Medical Center; Ols: Opportunistic Infections

\section{Acknowledgments}

The authors thank the study participants, data collectors and all staff members of Jimma Medical Center for their kind cooperation in conducting this thesis. We also would like to thank Jimma University for allowing us to conduct this research.

\section{Authors' contributions}

TA: Conceive the study, collect and analyse the data, draft the manuscript. FB: Conceive the study, collect and analyse the data. Gz: Conceive the study, analyse the data and review the manuscript. All authors have read and approved the manuscript.

\section{Funding}

Not applicable.

\section{Availability of data and materials}

The datasets and materials used in our study are available from the corresponding author on reasonable request.

\section{Ethics approval and consent to participate}

The study was approved by Institutional Review Board (IRB) of Institute of health sciences, Jimma University.

\section{Consent for publication}

Not applicable.

\section{Competing interests}

The authors of this paper have no competing interest.

\section{Author details}

'Department of clinical pharmacy, School of Pharmacy, Institute of Health Sciences, Jimma University, Jimma, Ethiopia. ${ }^{2}$ Department of Pharmacy, College of Medicine and Health Science, Dilla University, Dilla, Ethiopia.

\section{Received: 18 December 2019 Accepted: 24 February 2020}

Published online: 03 March 2020

\section{References}

1. Joint United Nations Programme on HIV/AIDS (UNAIDS). Report on the global AIDS epidemic. Geneva: UNAIDS; 2018. p. 1-6. Available from: http:// www.unaids.org/en/resources/fact-sheet. Accessed 14 Dec 2019

2. UNAIDS. The gap report, 2014. http://www.unaids.org/sites/default/files/en/ media/unaids/contentassets/documents/unaidspublication/2014/UNAIDS_ Gap report en.pdf (Accessed 14 Dec 2019).

3. Negera GZ, Mega TA. Clinical outcome of admitted HIV/AIDS patients in Ethiopian tertiary care settings: a prospective cohort study. PLoS one. 2019: 14(12):e0226683. https://doi.org/10.1371/journal.pone.0226683.

4. National guidelines for comprehensive HIV prevention, care and treatment. 2017; 1-236. Available from: https://aidsfree.usaid.gov/sites/ default/files/resources/ethiopia_art_guidelines_2017.pdf. Accessed 15 Dec 2019.

5. Gibb DM, Duong T, Tookey PA, Sharland M, Tudor-Williams G, Novelli, et al. Decline in mortality, AIDS, and hospital admissions in perinatally HIV-1 infected children in the United Kingdom and Ireland. BMJ. 2003;327: 1019-23.

6. Negera GZ, Mega TA. Health-related quality of life among admitted HIV / AIDS patients in selected Ethiopian tertiary care settings : a crosssectional study. Open Public Health J. 2019;12:532-40.
7. L'Homme RF, Kabamba D, Ewings FM, et al. Nevirapine, stavudine and lamivudine pharmacokinetics in African children on paediatric fixed-dose combination tablets. AIDS. 2008;22:557-65.

8. World Health Organization. Antiretroviral therapy for HIV infection in infants and children: towards universal access - 2010 revision. Geneva: World Health Organization; 2010. rev. ed. Accessed 25 Dec 2019.

9. WHO. Consolidated guidelines on the use of antiretroviral drugs for treating and preventing HIV infection: recommendations for a public health approach.https://apps.who.int/iris/bitstream/handle (Accesed 15 Dec 2019)

10. Purswani M, Patel K, Kopp JB, et al. Tenofovir treatment duration predicts proteinuria in a multiethnic United States cohort of children and adolescents with perinatal HIV-1 infection. Pediatr Infect Dis J. 2013:32:495-500.

11. Mulenga V, Musiime V, Kekitiinwa A. CHAPAS-3 trial team Abacavir, zidovudine, or stavudine as paediatric tablets for African HIV-infected children (CHAPAS-3): an open-label, parallel-group, randomised controlled trial. Lancet Infect Dis. 2016;16:169-79.

12. Nahirya-Ntege $P$, Musiime $V$, Naidoo B, et al. Low incidence of abacavir hypersensitivity reaction among African children initiating antiretroviral therapy. Pediatr Infect Dis J. 2011;30:535-7.

13. Munderi $P$, Snowden WB, Walker AS, et al. Distribution of HLA-B alleles in a Ugandan HIV-infected adult population: NORA pharmacogenetic substudy of DART. Tropical Med Int Health. 2011;16:200-4.

14. van Leth F, Phanuphak P, Ruxrungtham K, Baraldi E, Miller S, Gazzard B, et al. Comparison of first-line antiretroviral therapy with regimens including nevirapine, efavirenz, or both drugs, plus stavudine and lamivudine: a randomised open-label trial, the 2NN study. Lancet. 2004; 363:1253-63.

15. Gallant JE, DeJesus E, Arribas JR, Pozniak AL, Gazzard B, Campo RE, Study 934 group. Tenofovir DF, emtricitabine, and efavrienz vs. zidovudine, lamivudine, and efavirenz for HIV. N Engl J Med. 2006;354 251-60.

16. Robbins GK, De Gruttola V, Shafer RW, Smeaton LM, Snyder SW, Pettinelli C, AIDS Clinical Trials Group 384 team, et al. Comparison of sequential three-drug regimens as initial therapy for HIV-1 infection. N Engl J Med. 2003:349:2293-303.

17. Bartlett J, Fath M, DeMasi R, Quinn J, Hermes A, Rousseau F. An updated meta-analysis of triple combination therapy in antiretroviralna"ive HIV-infected adults. Boston: Twelfth Conference on Retroviruses and Opportunistic Infections; 2005.

18. Paediatric European Network for the Treatment of AIDS (PENTA). Lamivudine/abacavir maintains virological superiority over zidovudine/ lamivudine and zidovudine/abacavir beyond 5 years in children. AIDS. 2007;21:947-55

19. Pediatric European Network for the Treatment of AIDS. Comparison of dual nucleoside-analogue reverse-transcriptase inhibitor regimens with and without nelfinavir in children with HIV-1 who have not previously been treated: the PENTA 5 randomised trial. Lancet. 2002;359:733-40.

20. $\mathrm{FMoH}$. Stavudine replacement strategy; 2013. p. 1-14.

21. Cassim H, Otwombe K, Lazarus E, Liberty A, Gray GE, Greeff OBW, et al. A retrospective case-cohort study comparing treatment outcomes in abacavir versus stavudine containing first line antiretroviral treatment regimens in children $<3 y$ rs old, at a paediatric programme based in Soweto, South Africa. PLoS One. 2017 12(7):1-10

22. Biressaw S, Abegaz WE, Abebe M, Taye WA, Belay M. Adherence to antiretroviral therapy and associated factors among HIV infected children in Ethiopia: unannounced homebased pill count versus caregivers' report. BMC Pediatr. 2013;13(1):132

23. Sharma SK, Soneja M. HIV \& immune reconstitution inflammatory syndrome ( IRIS ). Indian J Med Res. 2011;134:866-77.

24. WHO. Patient monitoring guidelines for HIV care and antretroviral therapy (ART); 2006. p. 101

25. Adetokunboh OO, Schoonees A, Balogun TAWC. Efficacy and safety of abacavir-containing combination antiretroviral therapy as first-line treatment of HIV infected children and adolescents: a systematic review and meta-analysis. BMC Infect Dis. 2015;15(1):1-13.

26. Weldegebreal T, Ahmed I, Muhiye A, Belete $S$, Bekele A, Kaba M. Magnitude of opportunistic diseases and their predictors among adult people living with HIV enrolled in care: national level cross sectional study, Ethiopia. BMC Public Health. 2018;18(1):1-11. 
27. Iroezindu MO, Ofondu EO, Hausler $\mathrm{H}$, Van Wyk B. Prevalence and risk factors for opportunistic infections in HIV patients receiving antiretroviral therapy in a resource-limited setting in Nigeria. AIDS Clin Rev. 2013;53:1-9.

28. Hussen S, Belachew T, Hussein N. Nutritional status of HIV clients receiving HAART: its implication on occurrence of opportunistic infection. Open Public Health J. 2017;10(1):208-14.

29. Madec $Y$, Laureillard D, Pinoges $L$, et al. Response to highly active antiretroviral therapy among severely immuno-compromised HIVinfected patients in Cambodia. AIDS. 2007;21(3):351-9.

30. Ou H-T, Lee T-Y, Li C-Y, et al. Incidence of diabetes-related complications in Chinese patients with type 1 diabetes: a population-based longitudinal cohort study in Taiwan. Diab Endocrinol Res. 2017;7(6):1-11.

31. Shah S, Whalen C, Kotler DP, Mayanja H, Namale A, Melikian G, et al. Severity of human immunodeficiency virus infection is associated with decreased phase angle, fat mass and body cell mass in adults with pulmonary tuberculosis infection in Uganda. J Nutr. 2001;131(11):2843-7.

32. Campbell IA, Dyson AJ. Lymph node tuberculosis: a comparison of various methods of treatment. Tubercle. 1977;58:171-9.

\section{Publisher's Note}

Springer Nature remains neutral with regard to jurisdictional claims in published maps and institutional affiliations.

Ready to submit your research? Choose BMC and benefit from:

- fast, convenient online submission

- thorough peer review by experienced researchers in your field

- rapid publication on acceptance

- support for research data, including large and complex data types

- gold Open Access which fosters wider collaboration and increased citations

- maximum visibility for your research: over $100 \mathrm{M}$ website views per year

At BMC, research is always in progress.

Learn more biomedcentral.com/submissions 